\title{
At the Cutting Edge
}

\section{Interaction of hsp90 with steroid receptors: organizing some diverse observations and presenting the newest concepts}

\author{
William B. Pratt \\ Department of Pharmacology, The University of Michigan Medical School, Ann Arbor, MI 48109, U.S.A.
}

Key words: Steroid receptor; Heat-shock protein; hsp90; Protein folding; Protein translocation; Docking complex

\section{Introduction}

During the $1980 \mathrm{~s}$, it became clear that several receptors in the steroid/thyroid hormone receptor family are bound to the $90-\mathrm{kDa}$ heat shock protein (hsp90), both in intact cells and after recovery of the unliganded receptors in hypotonic cell lysates. Several laboratories have demonstrated that glucocorticoids and progestins promote the temperature-dependent dissociation of their respective receptors from hsp90. Again, this was shown both in intact cells and in cytosol preparations. Because dissociation of the receptor-hsp 90 complex is accompanied by conversion of the receptor from a non-DNA-binding to a DNA-binding state and because the dissociation is promoted by the binding of steroid to the receptor, the system has attracted considerable interest among endocrinologists as a model for studying how hormone binding can trigger the conversion of a transcriptional regulatory protein from an inactive to an active state.

The work of the 1980s, which established that the binding of hsp90 is correlated with the nonDNA-binding state of several steroid receptors, that the hormone binding domain of the receptor is the site of hsp90 association, and that steroids promote dissociation of receptor-hsp90 complexes,

Address for correspondence: William B. Pratt, Department of Pharmacology, The University of Michigan Medical School, 6322 Medical Science Building I, Ann Arbor, MI 48109-0626, U.S.A has been reviewed previously (see Pratt, 1987; Pratt et al, 1989). It is the purpose of this minireview to present some new concepts emanating from papers published between early 1989 and September of 1990, as well as from unpublished work that is in press and in progress. Specifically, I wish to address the following questions. What is the relationship between hsp 90 binding and the tight versus loose association of various members of the steroid/thyroid hormone receptor family with the cell nucleus? What is the receptor-hsp90 complex derived from? What are potential natural functions of hsp90, and what are the advantages of a receptor-hsp 90 interaction?

The concept of a receptor docking complex determined by binding to hsp90

After their synthesis (and probably also during the course of recycling following a drop in hormone level) unliganded progesterone, estrogen and androgen receptors are transported into the nucleus (King and Greene, 1984; Welshons et al., 1984; Perrot-Applanat et al., 1985) where they remain in an inactive 'docking' complex until the binding of hormone triggers a progression of the receptor to high affinity nuclear binding sites where the primary events involved in transcriptional activation occur. The docking state of the receptors is only loosely associated with the nucleus, and when cells are ruptured in hypotonic buffer, these receptors are recovered in the cytosolic fraction in a complex with hsp 90 . 
In contrast to the sex hormone receptors, the unliganded form of the glucocorticoid receptor is often retained in the cytoplasm (e.g. Antakly and Eisen, 1984; Qi et al., 1989) in a docking complex that also contains hsp90. However, unliganded glucocorticoid receptors can enter a nuclear docking complex in the same manner as the sex hormone receptors. We have recently shown, for example, that mouse glucocorticoid receptors overexpressed in hormone-free CHO cells are located entirely within the nucleus in an hsp90containing docking complex (Sanchez et al., 1990). The reason why this overexpressed glucocorticoid receptor localizes to the nucleus is unknown, but this example suggests that there is no great fundamental difference in the way unliganded glucocorticoid and sex hormone receptors are transported and docked within the cell.

Clear differences do exist between different receptors in the steroid/thyroid hormone receptor family with respect to their ability to bind hsp 90 , the avidity of hsp90 binding, and the requirement of hsp90 for steroid binding. In Table 1, the steroid/thyroid hormone receptors have been divided into different classes according to their hsp 90 binding properties.

Although glucocorticoid, estrogen and progesterone receptors all bind hsp90, the receptors appear to differ with respect to a requirement of hsp90 for steroid binding activity. There is now strong evidence that hsp90 must he hound to the glucocorticoid receptor for the hormone binding domain to be in a high affinity hormone binding conformation (Bresnick et al., 1989; Dalman et al., 1989; Meshinchi et al., 1990; Nemoto et al., 1990; Scherrer et al., 1990), whereas estrogens have been reported to bind to the purified receptor protein. Unliganded dioxin (Ah) receptors are also bound to hsp90 (Perdew, $1 \overline{988}$ ), but much less is known about this receptor, and it is not known if the hsp 90 -free receptor binds dioxin. In rat liver cytosol, the dioxin receptor-hsp90 complex is readily

\section{TABLE 1}

\section{CLASSIFICATION OF RECEPTORS IN THE STEROID/THYROID RECEPTOR FAMILY ACCORDING TO THEIR ASSOCIATION WITH hsp 90}

Receptors in parentheses have been tentatively assigned to the class on the basis of partial information. The superscripts reflect items that have not been demonstrated but can be reasonably predicted on the basis of receptor behavior.

\begin{tabular}{|c|c|c|}
\hline$\overline{C l a s s}$ & Description & Receptors in Class \\
\hline 1 & $\begin{array}{l}\text { (a) Receptors do not form a complex with hsp } 90 \text {. } \\
\text { (b) Unliganded receptors move directly to tight association with the nucleus. }\end{array}$ & $\begin{array}{l}\text { Thyroid hormone } \\
\text { Retinoic acid } \\
\text { (Vitamin D) }^{\text {a }}\end{array}$ \\
\hline II & $\begin{array}{l}\text { (a) Receptor forms complex with hsp90. } \\
\text { (b) hsp } 90 \text { is required for a high affinity steroid binding conformation. } \\
\text { (c) Unliganded receptor is retained in a cytoplasmic-nuclear docking complex } \\
\text { that is recovered in the cytosolic fraction after cell rupture. } \\
\text { (d) Steroid promotes temperature-dependent dissociation of hsp90 } \\
\text { from the receptor in intact cell and cytosol. }\end{array}$ & $\begin{array}{l}\text { Glucocorticoid } \\
\text { (Mineralocorticoid) }^{\text {b,d }}\end{array}$ \\
\hline III & $\begin{array}{l}\text { (a) Receptor forms stable complex with hsp90. } \\
\text { (b) hsp } 90 \text { not required for high affinity ligand binding conformation. } \\
\text { (c) Unliganded receptor is retained in a nuclear docking complex } \\
\text { that is recovered in the cytosolic fraction. } \\
\text { (d) Steroid promotes temperature-dependent dissociation of hsp90 } \\
\text { from the receptor in intact cell and cytosol. }\end{array}$ & $\begin{array}{l}\text { Progestin } \\
\text { Estrogen } \\
\text { (Androgen) }\end{array}$ \\
\hline IV & $\begin{array}{l}\text { (a) Stability of the receptor-hsp } 90 \text { complex varies with different species. } \\
\text { (b) Unknown whether hsp } 90 \text { is required for steroid binding conformation. } \\
\text { (c) Unliganded receptor is retained in a docking complex } \\
\text { that is recovered in the cytosolic fraction. } \\
\text { (d) Ligand promotes dissociation of receptor from hsp } 90 \text { in intact cell but } \\
\text { dioxin has not been shown to promote dissociation of the complex in cytos }\end{array}$ & Dioxin \\
\hline
\end{tabular}


dissociated by salt and stabilized by molybdate. Thus, in rat liver cytosol the dioxin receptor and the glucocorticoid receptor have very similar physical properties (Wilhelmsson et al., 1986). In mouse cytosol, however, the dioxin receptor-hsp90 complex is not dissociated by high salt (Cuthill et al., 1987; Denison and Vella, 1990), and in that respect it behaves more like the exceptionally stable complex between pp $60^{\text {src }}$ and hsp 90 than like other steroid receptor-hsp 90 complexes. To reflect these species-specific differences, the dioxin receptor has been assigned to a separate class in Table 1.

In contrast to the steroid receptors, receptors for thyroid hormone (Samuels et al., 1988) and retinoic acid (Nervi et al., 1989) become tightly associatcd with the nucleus in hormone-frce cclls. Thus, they do not enter a docking complex and high salt is required to extract the unliganded receptor from nuclei. Using a cell-free rabbit reticulocyte lysate translation system, we have recently shown that these two receptors are not bound to hsp90 (Dalman et al., 1990, 1991). This stands in contrast to glucocorticoid and sex hormone receptors, which are bound to hsp 90 after translation under the same conditions. Because the Class I receptors do not bind hsp90 and do not enter a docking complex, whereas unliganded receptors in Classes II-IV are both bound to hsp90 and retained in a docking complex, it is reasonable to conclude that hsp90 is the determinant (or at least a major determinant) of the docking state.

The docking complex is composed of several heat shock proteins

Because the steroid receptor-hsp90 complex could be studied in a direct manner and because the presence or absence of hsp 90 could be correlated with different functional states of the receptors, the majority of the work on steroid receptorassociated proteins has focused on hsp90. Hsp90 is a dimeric protein, and Mendel and Orti (1988) have determined that the stoichiometry of the heteromeric glucocorticoid receptor complex in cytosol is two molecules of hsp90 to one molecule of receptor. Aranyi et al. (1988) and Rexin et al. (1988) have used cross-linking techniques to show that hsp90 is directly bound to progesterone and glucocorticoid receptors, respectively. When unliganded glucocorticoid receptors are isolated from cytosol under the gentlest conditions designed to maintain as much of the structure of the native receptor complex as possible, it is clear that higher order complexes can be readily detected (Bresnick et al, 1990). The higher order complexes for $L$ cells were found to contain more than one hsp 90 dimer per receptor, as well as other proteins of apparent $M_{\mathrm{r}} 23,000$ and 55,000. Thus, it appears that the complex containing one molecule of receptor and two molecules of hsp90 is a core unit derived from a larger heteromeric complex of proteins.

A second known component of the receptor docking complex is hsp70. Kost et al. (1989) and Smith et al. (1990a) have shown that rapid gentle immunoadsorption of avian progesterone receptors results in the immunospecific isolation of four proteins of approximately $70,54,50$ and $23 \mathrm{kDa}$ in addition to hsp 90 . The $70 \mathrm{kDa}$ protein has been identified as the constitutive form of hsp70. The $76 \mathrm{kDa}$ protein that was previously reported to copurify with the human progesterone receptor (Estes et al., 1987) is apparently also a member of the hsp 70 family (Smith et al., 1990a). Although steroid-dependent transformation of the progesterone receptor results in hsp90 dissociation, hsp70 remains bound to the receptor, implying that, like hsp90, hsp70 interacts directly with the receptor protein (Smith et al., 1990a).

Hsp70 is not associated with mouse glucocorticoid receptors immunoadsorbed from $\mathrm{L}$ cell cytosol (Bresnick et al., 1990; Sanchez et al., $1990 \mathrm{~b}$ ), but hsp70 is clearly a component of the receptor heterocomplex immunoadsorbed from CHO cells that overexpress the mouse glucocorticoid receptor (Sanchez et al., 1990b). Although in both cases it is the mouse glucocorticoid receptor heterocomplex that is being isolated, in the case of $L$ cells the docking complex appears to be located predominantly in the cytoplasm, whereas in the overexpressing $\mathrm{CHO}$ cells it is located solely in the nucleus. The isolation of hsp70 in association with nuclear receptors leads to the speculation that hsp70 is in some way related to arrival of steroid receptors at a nuclear docking complex. 
Glucocorticoid and progesterone receptors are larger than the limits estimated for passage of molecules into the nucleus by diffusion, implying that they must pass into the nucleus via an as yet undefined transport process. Hsp70 is known to play a role in the passage of proteins across the membranes of the endoplasmic reticulum and mitochondria. The heat shock protein is thought to facilitate protein unfolding and it is known that certain organellar proteins have to be maintained in an unfolded state to cross these membranes (for review, see Pelham, 1988; Rothman, 1989). At the risk of the accusation of unrestrained speculation, it is possible that hsp 70 could play a role in maintaining the steroid receptors in an unfolded state for passage across the nuclear membrane.

Another established component of the receptor docking complex is a $56-59 \mathrm{kDa}$ protein. This protein was first identified when Nakao et al. (1985) developed a monoclonal antibody against a crudely purified $9 \mathrm{~S}$ progestin receptor that was shown to immunoadsorb nontransformed rabbit uterine progestin receptor complexes (Tai and Faber, 1985). This EC1 antibody reacts specifically with a $59 \mathrm{kDa}$ rabbit protein that is also contained in 9S untransformed estrogen, androgen and glucocorticoid receptor complexes in cytosols prepared from rabbit tissues (Tai et al., 1986). The human protein recognized by this $\mathrm{EC} 1$ antibody is a $56 \mathrm{kDa}$ protein with several isomorphic forms that is located predominantly in the cytoplasm but also within the nucleus of human cells (Sanchez et al., 1990a). It is likely that the $55 \mathrm{kDa}$ protein reported to be associated with the mouse glucocorticoid receptor (Bresnick et al., 1990) and the $54 \mathrm{kDa}$ protein associated with the chicken progesterone receptor (Smith et al., 1990a) are the same as this $56-59 \mathrm{kDa}$ protein. This identity has not been established, however, because of the failure of the $\mathrm{ECl}$ antibody to react with mouse or chicken proteins.

Sanchez et al. (1990a) have shown that immunoadsorption of p56 from human IM- 9 cell cytosol with EC1 antibody results in the co-isolation of substantial amounts of both hsp70 and hsp90, as well as minor amounts of proteins of 23 , 35 and $120 \mathrm{kDa}$. As neither hsp70 nor hsp90 reacts directly with the $\mathrm{EC} 1$ antibody, it must be concluded that p56 exists in cytosol in a higher order complex that contains both of these heat shock proteins. Sanchez (1991) has shown that p56 is synthesized at an increased rate when IM-9 cells are heat shocked. Thus, p56 appears to be a previously unrecognized heat shock protein of relatively low abundance (compared to hsp70 and hsp90), and it can now be referred to as hsp56-59 to encompass the range of values of $M_{\mathrm{r}}$ estimated in different species. Renoir et al. (1990) have cross-linked the proteins in the $9 \mathrm{~S}$ forms of rabbit progestin, estrogen, androgen and glucocorticoid receptors and have identified hsp56-59 in the cross-linked products. Their results indicate that p59 is bound to hsp90 and is not directly associated with the receptors themselves.

It should also be mentioned that Perdew (1991) has used the 8D3 monoclonal antibody against hsp90 to identify hsp90-associated proteins in mouse hepatoma (Hepa 1c1c7) cytosol. Two of these proteins identified by Western blotting are hsp70 and a $56 \mathrm{kDa}$ protein that reacts with a polyclonal antibody developed against the $\mathrm{ECl}$ antigen. Thus, the picture has emerged that hsp56-59 and a fraction of both hsp70 and hsp90 are associated in a complex that exists in cytosols prepared from several species. This complex exists independently of steroid receptors and it appears to be present in considerable stoichiometric excess with respect to the receptors (Sanchez et al., 1990a). It is reasonable to propose that the docking complex reflects the attachment of the receptors to a heat shock protein-containing complex that performs some type of general function in the cell.

\section{Potential natural functions of hsp90}

Hsp90 is a conserved, ubiquitous, abundant, essential, and predominantly cytoplasmic protein (for review see Lindquist and Craig, 1988). Members of the hsp90 gene family have been cloned from bacteria, yeast, trypanosomes, Drosophila, birds and mammals; the hsp90 proteins display amino acid sequence identity in excess of $40 \%$; and a member of the hsp 90 gene family has been found in all species examined. In $\mathrm{L}$ cells as well as in many other eukaryotic cells, hsp90 comprises approximately $1 \%$ of the total cytosolic protein and its rate of synthesis is increased by heat and 
other stress conditions. Although hsp90 does appear to play a role in thermotolerance, its constitutive presence is essential for normal eukaryotic cell function (Borkovich et al., 1989). It has been shown, for example, that deletion of the hsp90 genes in $S$. cerevisiae is lethal to that organism, even at $25^{\circ} \mathrm{C}$ (Borkovich et al., 1989).

The natural and essential function of this abundant protein is unknown, but three possible functions that have been suggested in the literature may be reflected in the steroid receptor interaction. One suggestion is that hsp 90 performs some type of chaperone function related to protein folding. From what is known about the glucocorticoid receptor-hsp 90 association such a general function is attractive. When the glucocorticoid receptor is translated in the cell-free rabbit reticulocyte system, the receptor becomes bound to hsp90 at or very near the termination of translation (Dalman et al., 1989). The association of hsp90 with steroid receptors does not represent a free thermodynamic equilibrium. That is, after dissociation of hsp90 from the receptor in cytosol, hsp90 does not reassociate with the receptor, even with the addition of huge amounts of purified hsp90 (Bresnick et al., 1989; Scherrer et al., 1990). Thus, it appears that the receptor undergoes a conformational change on dissociation from hsp 90 that leaves it unable to freely reassociate with the heat shock protein. Indeed, there is now direct evidence that after hsp90 dissociates from the receptor in cytosol, a significant portion of the receptors collapse into a misfolded state that cannot bind to DNA unless the hormone-binding domain is removed (Hutchison et al., 1991).

Smith et al. (1990b) have shown that incubation of immunoadsorbed, hsp90-free chicken progesterone receptors with rabbit reticulocyte lysate results in the temperature-dependent association of the chicken receptor with rabbit hsp90 and hsp70. The unliganded receptor undergoes reconstitution but the liganded receptor does not, consistent with the role of the ligand in promoting hsp90 dissociation. Scherrer et al. (1990) have demonstrated a similar reconstitution of the murine glucocorticoid receptor with the rabbit reticulocyte hsp90. The reconstitution of the complex is accompanied by conversion of the receptor from a DNA-binding to a non-DNA-binding state and a reconstitution of the stcroid binding conformation.

Currently, we interpret this reticulocyte lysatemediated reconstitution as a temperature-dependent unfolding of the receptor accompanied by hsp90 binding and stabilization of the unfolded state. In both the case of the progesterone receptor and the glucocorticoid receptor, the reconstituted complex also contains hsp70, although with the glucocorticoid receptor this is not as readily demonstrated as with the progesterone receptor. Given the proposed unfoldase activity of hsp70 in other systems (see Rothman, 1989), hsp70 is a reasonable candidate for the proposed unfolding requirement in the receptor-hsp90 reconstitution system. Picard et al. (1988) have suggested on theoretical grounds that hsp 90 may itself act as an unfoldase. As we find that purified hsp90 does not reconstitute the receptor-hsp 90 complex and it does not have ATPase activity, I would suggest that the role of hsp90 is to trap the unfolded state.

A second general function suggested for hsp 90 is to stabilize proteins against degradation in the cell. It is known that in cytosols containing extensive protease activity (e.g. rat liver cytosol) molybdate partially stabilizes the glucocorticoid receptor to degradation (Bresnick et al., 1988). As all of the other effects of molybdate on steroid receptors can be attributed to stabilization of receptor-hsp90 complexes, we have suggested that binding to hsp90 stabilizes the receptor to proteolysis in cytosol. There is evidence for such stabilization in intact cells as well. Housley et al. (1990) have shown that a mutant mouse glucocorticoid receptor deleted for the highly conserved region in the steroid binding domain (residues 574-632) undergoes extensive intracellular cleavage. This mutant receptor is bound to hsp90 but the complex appears to be much less stable than that of the wild-type receptor. As hsp90 itself is quite stable to proteolysis by endogenous cytosolic proteases, it is not surprising that a receptor complexed with it might be more stable. In the case of steroid receptors, a function of hsp 90 related to protein folding and a function related to stabilization to proteolysis can probably both be viewed as two sides of the same coin.

A third function that has been suggested for hsp90 is a role in a receptor transport (Schlesinger, 
1986; Sanchez et al., 1988). This proposal was first made for $\mathrm{pp} 60^{\mathrm{src}}$, where the newly synthesized viral protein is bound to hsp90 until it becomes associated with the plasma membrane (Brugge, 1986). At this time, hsp 90 has not been shown to play a role in steroid receptor transport, although it seems highly likely that hsp90 must be associated with steroid receptors during their transport from cytoplasmic sites of synthesis to nuclear docking sites. This is inferred from the fact that hsp90 binds to the glucocorticoid receptor at the termination of cell-free receptor translation (Dalman et al., 1989), and it is entirely possible that hsp90 binding to the receptor is coupled with or occurs proximate to receptor translation in vivo. The mechanism of steroid receptor transport is unknown (microtubule-based? actin-based?), but it is known that the receptor gets transported to and probably within the nucleus in a manner that is determined by specific nuclear localization signals (Picard and Yamamoto, 1987).

Whatever the mechanism of nuclear transport may be, the nuclear docking complexes for steroid receptors may lie at the terminus of the transport pathway. Unliganded glucocorticoid receptors in nuclear docking complexes of receptor-overexpressing CHO cells have been examined by confocal microscopy using indirect immunofluorescence for detection (Martens et al., 1991). The receptors are distributed in a mottled pattern throughout all planes of the nucleus but are not distributed to nucleoli. There is no apparent change in receptor distribution within the nucleus when the cells are exposed to steroid and receptors move from their loosely-bound docking state to high affinity association with nuclear components. The distribution of the receptor in the nucleus is clearly nonrandom, as there are multiple punctate areas from which the receptor is excluded. As the unliganded receptors are associated with both hsp 90 and hsp 70 (Sanchez et al., 1990b), they are by definition in docking complexes, and it is a reasonable speculation that the docking complexes lie at or near multiple termini of the receptor nuclear transport pathway. As discussed above, it is possible (and even likely) that hsp90 is present in such docking complexes because it has been carried along with the receptor whose nuclear localization signal has determined an association with the transport mechanism. By this line of reasoning the relationship of hsp90 to receptor transport is that of a passive copassenger and not that of the active participant we have previously suggested (Redmond et al., 1989). This analysis is also consistent with a primary function for hsp90 in protein folding and stabilization as outlined above.

\section{What is the advantage of a receptor-hsp90 interac- tion?}

In considering the evaluation of a steroid receptor-hsp90 interaction, one concept that can probably be eliminated is that the interaction is required for there to be any hormone effect on transcription. This statement is based on the fact that thyroid hormone and retinoic acid receptors do not form a stable association with hsp90, yet their ability to enhance transcription is clearly hormone-dependent. On the basis of analysis of amino acid homology within conserved regions of receptors in the steroid/thyroid hormone receptor family, McDonnell et al. (1988) and O'Malley (1989) have developed the strong argument that the receptors for vitamin $\mathrm{D}$, thyroid hormone and retinoic acid (Class I receptors in Table I) evolved before the steroid receptors. If these receptors are more primitive than the steroid hormone receptors, then the ability to have ligand-regulated transcriptional activation evolved before receptor association with hsp90.

One can ask why association of steroid receptors with hsp90 would yield a higher level of evolutionary development in the signal transduction pathway. The answer may lie in the proposal that the hsp90-bound receptor held in a docking complex is completely inactive until it is released from that state by hormone. There is evidence that unliganded forms of the Class I receptors can bind to hormone response elements and that the unliganded receptors may repress transcription directed from their own elements (e.g. TR acting on a TRE) or from other elements with which they interact (e.g. TR acting on a RARE). Thus, a complicated mixture of possible responses may exist depending upon the concentrations of several hormones and the integration of negative and positive effects on transcription. Retention of the Class II-IV receptors in a docking complex 
eliminates any effect of the unbound receptor on transcription, allowing the hormone to turn on the receptor like a switch; that is, from no activity to transcriptional enhancement. Although some cross-interaction is allowed at the level of ligand binding (e.g. binding of cortisol to both glucocorticoid and mineralocorticoid receptors) and although there may be some interaction of liganded receptors at the level of the SREs, a considerable amount of noise has been taken out of the system in the evolution of an hsp90-bound docking complex.

The docking complex could have evolved from a general role of hsp90 in protein folding and stabilization. Members of the hsp 70 family have been shown to interact cotranslationally with a variety of proteins (Beckmann et al., 1990), an association that is probably necessary for both proper protein folding and for protein translocation (Rothman, 1989). It is possible that hsp90 also associates transiently with a variety of proteins during or at the termination of their synthesis in the intact cell. Indeed, this may be the case with the Class I receptors, but the complex is transient and cannot be detected with our methods. As suggested in Dalman et al. (1989), the steroid receptors may have evolved both a higher affinity association with hsp90 and a mechanism of signal transduction in which their dissociation from this primitive and necessary cellular protein is under hormonal control.

\section{Acknowledgements}

The author's work was supported by grant DK31573 from the National Institutes of Health and grant CA28010 from the National Cancer Institute. I thank David Toft, Michel Renoir, Edwin Sanchez and Gary Perdew for their helpful discussion and for communicating results prior to publication.

\section{References}

Antakly, T. and Eisen, H.J. (1984) Endocrinology 115, 1984 1989.

Aranyi, P., Radanyi, C., Renoir, M., Devin, J. and Baulieu, E.E. (1988) Biochemistry 27, 1330-1336.
Beckman, R.P., Mizzen, L.A. and Welch, W.J. (1990) Science 248, 850-854.

Borkovich, K.A., Farrelly, F.W., Finkelstein, D.B., Taulien, J. and Lindquist, S. (1989) Mol. Cell. Biol. 9, 3919-3930.

Bresnick, E.H., Sanchez, E.R., Harrison, R.W. and Pratt, W.B. (1988) Biochemistry 27, 2866-2872.

Bresnick, E.H., Dalman, F.C., Sanchez, E.R. and Pratt, W.B. (1989) J. Biol. Chem. 264, 4992-4997.

Bresnick, E.H., Dalman, F.C. and Pratt, W.B. (1990) Biochemistry $29,520-527$.

Brugge, J.S. (1986) Curr. Top. Microbiol. Immunol. 123, 1-22.

Cuthill, S., Poellinger, L. and Gustafsson, J.A. (1987) J. Biol. Chem. 262, 3477-3481.

Dalman, F.C., Bresnick, E.H., Patel, P.D., Perdew, G.H., Watson, S.J. and Pratt, W.B. (1989) J. Biol. Chem. 264, 1981519821.

Dalman, F.C., Koenig, R.J., Perdew, G.H., Massa, E. and Pratt, W.B. (1990) J. Biol. Chem. 265, 3615-3618.

Dalman, F.C., Sturzenbecker, L.J., Levin A.A., Lucas, D.A., Perdew, G.H., Petkovich, M., Chambon, P., Grippo, J.F. and Pratt, W.B. (1991) Submitted manuscript.

Denison, M.S. and Vella, L.M. (1990) Arch. Biochem. Biophys. 277, 382-388

Estes, P.A., Suba, E.J., Lawler-Heavner, J., Elashry-Stowers, D., Wei, L.L., Toft, D.O., Sullivan, W.P., Horwitz, K.B. and Edwards, D.P. (1987) Biochemistry 26, 6250-6262.

Housley, P.R., Sanchez, E.R., Danielsen, M., Ringold, G.M. and Pratt, W.B. (1990) J. Biol. Chem. 265, 12778-12781.

Hutchison, K.A., Matić, G., Meshinchi, S., Bresnick, E.H. and Pratt, W.B. (1991) Submitted manuscript.

King, W.J. and Greene, G.L. (1984) Nature 307, 745-747.

Kost, S.L., Smith, D., Sullivan, W., Welch, W.J. and Toft, D.O. (1989) Mol. Cell. Biol. 9, 3829-3838.

I indquist, S. and Craig, E.A. (1988) Annu. Rev. Genet. 22, 631-677.

Martens, V.R., Pratt, W.B., Hirst, M.A., Ringold, G.M. and Housley, P.R. (1991) Submitted manuscript.

McDonnell, D.P., Pike, J.W. and O'Malley, B.W. (1988) J. Steroid Biochem. 30, 41-46.

Mendel, D.B. and Orti, E. (1988) J. Biol. Chem. 263, 6695-6702.

Meshinchi, S., Sanchez, E.R., Martell, K.J. and Pratt, W.B. (1990) J. Biol. Chem. 265, 4863-4870.

Nakao, K., Myers, J.E. and Faber, L.E. (1985) Can. J. Biochem. Cell Biol. 63, 33-40.

Nemoto, T., Ohara-Nemoto, Y., Denis, M. and Gustafsson, J.A. (1990) Biochemistry 29, 1880-1886.

Nervi, C., Grippo, J.F., Sherman, M.I., George, M.D. and Jetten, A.M. (1989) Proc. Natl. Acad. Sci. U.S.A. 86, 58545858.

O'Malley, B.W. (1989) Endocrinology 125, 1119-1120.

Pelham, H. (1988) Nature 332, 776-777.

Perdew, G.H. (1988) J. Biol. Chem. 263, 13802-13805.

Perdew, G.H. (1991) Submitted manuscript.

Perrot-Applanat, M., Logeat, F., Groyer-Picard, M.T. and Milgrom, E. (1985) Endocrinology 116, 1473-1484.

Picard, D. and Yamamoto, K.R. (1987) EMBO J. 6, 3333-3340.

Picard, D., Salser, S.J. and Yamamoto, K.R. (1988) Cell 54, 1073-1080. 
Pratt, W.B. (1987) J. Cell. Biochem. 35, 51-68.

Pratt, W.B., Redmond, T., Sanchez, E.R., Bresnick, E.H., Meshinchi, S. and Welsh, M.J. (1989) in The Steroid/ Thyroid Hormone Receptor Family and Gene Regulation (Carlstedt-Duke, J. et al., eds.), pp. 109-126, BirkhauserVerlag, Basel.

Qi, M., Hamilton, B.J. and DeFranko, D. (1989) Mol. Endocrinol. 3, 1279-1288.

Redmond, T., Sanchez, E.R., Bresnick, E.H., Schlesinger, M.J., Toft, D.O., Pratt, W.B. and Welsh, M.J. (1989) Eur. J. Cell Biol. 50, 66-75.

Renoir, J.M., Radanyi, C., Faber, L.E. and Baulieu, E.E. (1990) J. Biol. Chem. 265, 10740-10745.

Rexin, M., Busch, W. and Gehring, U. (1988) Biochemistry, 27, 5593-5601.

Rothman, J.E. (1989) Cell 59, 591-601.

Samuels, H.H., Forman, B.M., Horowitz, Z.D. and Ye, Z.S. (1988) J. Clin. Invest. 81, 957-967.

Sanchez, E.R. (1991) Submitted manuscript.

Sanchez, E.R., Faber, L.E., Henzel, W.J. and Pratt, W.B. (1990a) Biochemistry 29, 5145-5152.
Sanchez, E.R., Hirst, M., Scherrer, L.C., Tang, H.-Y., Welsh, M.J., Harmon, J.M., Simons, Jr., S.S., Ringold, G.M. and Pratt, W.B. (1990b) J. Biol. Chem. (in press).

Scherrer, L.C., Dalman, F.C., Massa, E., Meshinchi, S. and Pratt, W.B. (1990) Submitted manuscript.

Schlesinger, M.J. (1986) J. Cell Biol. 103, 321-325.

Smith, D.F., Faber, L.E. and Toft, D.O. (1990a) J. Biol. Chem. 265, 3996-4003.

Smith, D.F., Schowalter, D.B., Kost, S.L. and Toft, D.O. (1990b) Mol. Endocrinol. (in press).

Tai, P.K. and Faber, L.E. (1985) Can. J. Biochem. Cell Biol. $63,41-49$.

Tai, P.K., Maeda, Y., Nakao, K., Wakim, N.G., Duhring, J.L. and Faber, L.E. (1986) Biochemistry 25, 5269-5275.

Welshons, W.V., Lieberman, M.E. and Gorski, J. (1984) Nature 307, 747-749.

Wilhelmsson, A., Wikstrom, A.C. and Poellinger, L. (1986) J. Biol. Chem. 261, 13456-13463. 